\title{
Diabetes and reactivity of isolated human saphenous vein
}

\author{
Robert J. Cardwell and R. Clinton Webb \\ Department of Physiology, University of Michigan Medical School, Ann Arbor, Michigan 48109, U.S.A.
}

(Received 21 October 1983; accepted 12 April 1984)

Summary. Helical strips of saphenous veins from diabetic $(n=8)$ and non-diabetic $(n=18)$ humans were studied in vivo for their responsiveness to several vasoactive agents. Following application of passive force $(\sim 20.0 \mathrm{mN})$, venous strips from non-diabetic humans often developed spontaneous phasic contractile activity (12 out of 18 patients; $2-5$ contractions $/ \mathrm{min}$ ). These intrinsic changes in force were seen in venous strips from only one diabetic patient. The phasic contractions were not altered by treatment with phentolamine, whereas the calcium channel blocker, D-600, and calcium-free solution ( $1.0 \mathrm{mM}$ EGTA) inhibited the phasic contractions. Saphenous veins from diabetic patients developed less maximal, active tension in response to norepinephrine than those from non-diabetic patients. Contractile responses to serotonin, angiotensin II, and elevated potassium concentration in saphenous veins from diabetic patients were not different from those in veins from non-diabetic patients. These observations demonstrate attenuated development of active tension in response to alpha-adrenergic receptor activation and reduced spontaneous contractile activity in venous smooth muscle from diabetic patients.

\section{Introduction}

Vascular reactivity and structural properties of the blood vessels are altered in experimental animal models of diabetes and in diabetic patients (for review see Altura, Halevy \& Turlapaty, 1979; Chobanian et al., 1982; West 1978). Although the experimental procedures vary between different studies (contractility and sensitivity to drug action in isolated vascular segments; pressor responsiveness in isolated vascular beds; pressor responsiveness in intact animals), it is usually observed that vascular responsiveness to angiotensin II is exaggerated in the diabetic state (Brody \& Dixon, 1964; Christlieb et al., 1976; Christlieb, 1974; Kaul \& Grewal, 1980), whereas vascular responses to catecholomines are either increased (Beretta-Piccoli \& Weidmann, 1981; Brody \& Dixon, 1964; Christlieb et al., 1976; Cseuz et al., 1973; Owen \& Carrier, 1980; Weidmann et al., 1979, decreased (Joyner et al., 1981; Foy \&

Correspondence: Dr R. Clinton Webb, Department of Physiology, 7813 Medical Science Building II, University of Michigan Medical School, Ann Arbor. Michigan 48109, U.S.A. 
Lucas, 1976; Sullivan \& Sparks, 1979) or unchanged (Christlieb et al., 1976; Christlieb, 1974; Joyner et al., 1981; Kaul \& Grewal, 1980) in diabetes compared to control values. Augmented pressor responsiveness to angiotensin II and norepinephrine in diabetic patients is correlated with retinopathy (Christlieb et al., 1976) and with mild hypertension (Weidmann et al., 1979).

The present study was designed to compare contractile responses to vasoactive agents in isolated saphenous veins from diabetic patients with those of veins from non-diabetic patients.

\section{Methods}

Saphenous veins from 18 non-diabetic patients and eight patients with diabetes mellitus were studied. The non-diabetic group included five females and 13 males ranging in age from 48 to 68 years. The diabetic patients included three females and five males ranging in age from 51 to 69 years. Diabetes mellitus was diagnosed by standard laboratory methods and its known duration ranged from 5 to 14 years (mean \pm standard error of mean $(\mathrm{SEM})=8 \pm 1$ years). All diabetic patients were treated by diet and/or insulin. None of the diabetic patients had clinically evident retinopathy, nephropathy, or autonomic neuropathy. Four of the non-diabetic patients and three of the diabetic patients were being treated for hypertension (known duration 8-12 years; these patients had blood pressures within normal limits at the time of experimentation). All patients had been admitted to the hospital for coronary artery bypass surgery.

Following surgery a segment of saphenous vein which was to be discarded was obtained and placed in cold physiological salt solution (PSS). The veins were cleaned of adherent fat and connective tissue and cut helically into strips $(1.5 \times 15 \mathrm{~mm})$ under a dissecting microscope. Two to 12 strips were cut from each vein. The helical strips were mounted vertically on a glass holder in a tissue bath containing PSS. The upper ends of the strips were connected to force transducers (Grass FT.03), and the resting force placed on each strip was adjusted so that the strip produced maximum active force in response to a standard dose of norepinephrine $\left(6.0 \times 10^{-6} \mathrm{M}\right)$. The bathing medium was maintained at $37^{\circ} \mathrm{C}$ and aerated with a mixture of $95 \% \mathrm{O}_{2}$ and $5 \% \mathrm{CO}_{2}$. The $\mathrm{pH}$ of the solution was $7 \cdot 2$ and the composition (mmol/l) was as follows: $\mathrm{NaCl}$ (130), $\mathrm{KCl}(4 \cdot 7), \mathrm{KH}_{2} \mathrm{PO}_{4}(1 \cdot 18), \mathrm{MgSO}_{4} 7 \mathrm{H}_{2} \mathrm{O}(1 \cdot 17), \mathrm{CaCl}_{2} 2 \mathrm{H}_{2} \mathrm{O}(1 \cdot 6), \mathrm{NaHCO}_{3}$ (14.9), dextrose (5.5) and $\mathrm{CaNa}_{2}$ EDTA (0.03). Higher concentrations of potassium $(10-100 \mathrm{mM})$ in the bathing medium were achieved by equimolar substitution of $\mathrm{NaCl}$ with $\mathrm{KCl}$. Before the start of experiments, the strips were allowed to equilibrate for $3 \mathrm{~h}$ in PSS.

Contractile responses to increasing concentrations of agonists (norepinephrine, serotonin, angiotensin II, potassium chloride) were obtained by a cumulative increase in the total concentration of the agonist in the bath. The tissue response was allowed to reach a stable plateau (2-5 min) before each successive concentration of the agonist 
was added. Contractile responses to elevated potassium concentrations were determined in the presence of $1.3 \times 10^{-6} \mathrm{M}$ phentolamine to eliminate the effects of norepinephrine released from adrenergic nerve endings in the vessel wall (Vanhoutte, Verbeuren \& Webb, 1981). Norepinephrine and serotonin were dissolved in $0.1 \%$ ascorbate and serially diluted in distilled water before cumulative addition to the muscle bath. Angiotensin II was dissolved and serially diluted in distilled water. Injection volumes for each drug were 15-35 $\mu \mathrm{l}$ per dose. Concentrations are expressed as $\mathrm{mol} / \mathrm{l}$ final concentration in the muscle bath.

Drugs used were: norepinephrine bitartrate (Sigma Chemical Co.), serotonin creatine sulphate (Sigma Chemical Co.), angiotensin II (synthetic human form, Sigma Chemical Co.), and phentolamine (Ciba Pharmaceuticals).

The results of these experiments were analyzed by several statistical procedures. In all experiments, the multiple strips cut from each vein segment were subjected to the same drugs and the responses of the multiple strips were averaged to give a mean response for that patient. Thus, the $\mathbf{N}$ values reported in the figures and text reflect the number of patients in each group. Unless stated otherwise, all reported values are the mean \pm standard error of the mean (SEM). The responses of each venous strip were normalized to its cross-sectional area in order to evaluate active tension development in response to different agonists between saphenous veins from the two patient groups. The cross-sectional area $\left(\mathrm{cm}^{2}\right)$ of each strip was estimated by dividing strip volume in $\mathrm{ml}$ (which equals strip weight in $\mathrm{g}$ assuming that the density of each venous strip is 1.0 ) by its length in $\mathrm{mm}$ at a passive force determined to be optimal for maximal force generation in response to norepinephrine $(\sim 20.0 \mathrm{mN}$ for all strips). To determine the dose of each drug which caused a half-maximal response $\left(E_{50}\right.$ value), the dose-response curves were converted to percent maximal response and $-\log E D_{50}$ values were determined by a least squares method following logit-log transformation. Statistical evaluation of the data was by the Student's $t$-test for unpaired samples. Chi square analysis was used to compared the incidence of phasic contractile activity between groups. A $P$ value less than 0.05 was considered to be statistically significant.

\section{Results}

\section{CLINICAL VARIABLES}

Compared with the 18 non-diabetic patients, the diabetic patients averaged slightly older and tended to have higher plasma glucose levels (Table 1). Heart rates, arterial blood pressures and body weights were comparable in the non-diabetic and diabetic patients. Plasma creatinine, sodium, potassium and calcium levels, measured under basal conditions, were comparable in the two groups (data not shown).

PHASIC CONTRACTILE ACTIVITY

Isolated saphenous vein strips from non-diabetic patients often developed phasic 
Table 1. Clinical variables in non-diabetic and diabetic patients (mean \pm SEM)

\begin{tabular}{lcc}
\hline & $\begin{array}{c}\text { Non-diabetic } \\
(n=18 ; 8 \text { females, 13 males })\end{array}$ & $\begin{array}{c}\text { Diabetic } \\
(n=8 ; 3 \text { females, 5 males })\end{array}$ \\
\hline Age (years) & $54 \pm 2$ & $59 \pm 2$ \\
Body weight $(\mathrm{kg})$ & $81 \pm 2$ & $84 \pm 4$ \\
Blood pressure $(\mathrm{mmHg})$ & $123 / 79 \pm 4 / 2$ & $133 / 80 \pm 7 / 5$ \\
Heart rate (beats/min) & $78 \pm 3$ & $76 \pm 2$ \\
Plasma glucose $(\mathrm{mg} / \mathrm{dl})$ & $125 \pm 5$ & $167 \pm 20$ \\
\hline
\end{tabular}

contractile activity (Fig. 1). These intrinsic changes in force were seen in six strips from only one of the diabetic patients (total number of strips $=56$ ), whereas these changes were seen in 62 strips of 12 of 18 non-diabetic subjects (total number of strips $=90$; Chi square analysis, $P<0 \cdot 05$ ). The frequency of the phasic contractions was 2-5 responses per $5 \mathrm{~min}$ interval and the magnitude of the force generated per contraction was comparable in veins from the two groups of patients (nondiabetic $=151 \pm 15 \mathrm{mN} / \mathrm{cm}^{2} ;$ diabetic $=148 \pm 25 \mathrm{mN} / \mathrm{cm}^{2}$ ). The phasic contractions were not altered by treatment with $10^{-6} \mathrm{M}$ phentolamine (Fig. 1). The phasic contractions were inhibited when the strips were placed in calcium-free PSS containing $1.0 \mathrm{mM}$ EGTA but appeared again when normal PSS was returned to the bath. The calcium channel blocker, D-600 $\left(10^{-6} \mathrm{M}\right)$, inhibited the phasic contractile responses in a reversible manner.

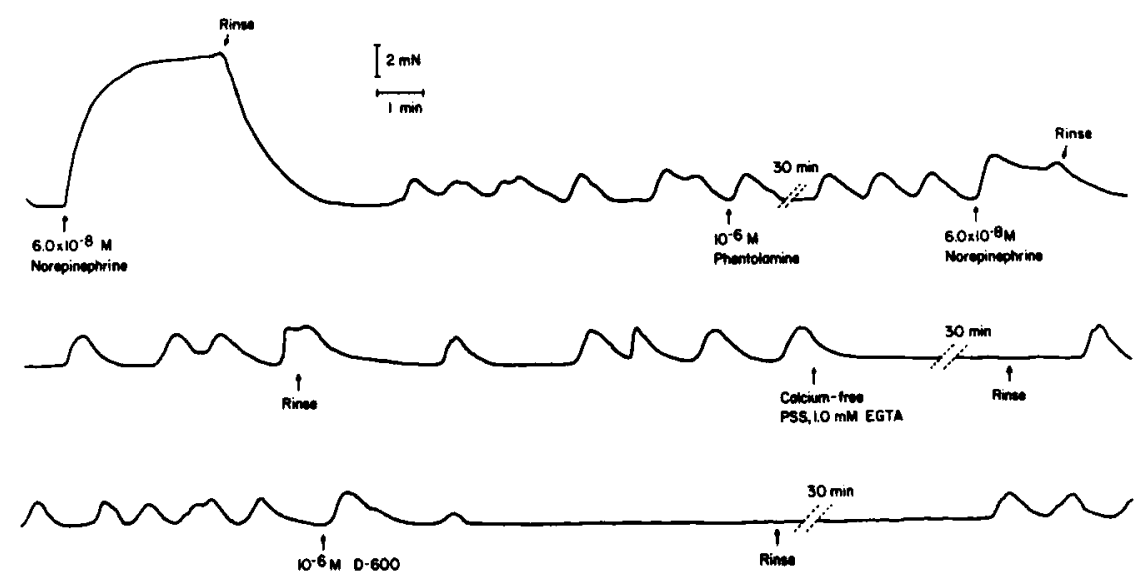

Fig. 1. Isometric force recording of an isolated saphenous vein strip from a non-diabetic patient. The top tracing illustrates that the phasic contractile responses were not blocked by the alpha-adrenergic antagonist, phentolamine $\left(10^{-6} \mathrm{M}\right)$. The phasic contractile activity was inhibited by treatment of the strip with calcium-free PSS containing 1.0 mM EGTA (middle tracing) and by the calcium channel blocker, D-600 (10 $0^{-6} \mathrm{M}$, bottom tracing). 


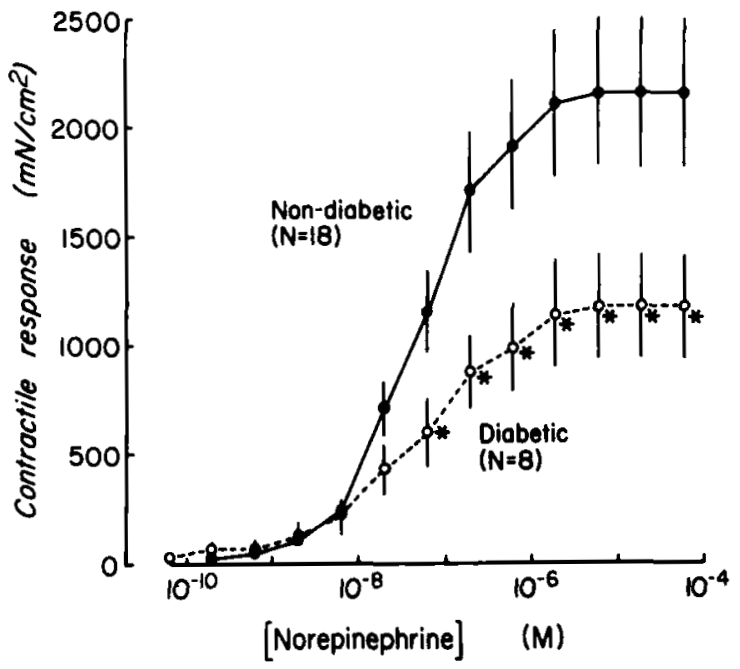

Fig. 2. Dose-response to norepinephrine. Helical strips of saphenous veins from non-diabetic patients were made to contract in response to the cumulative addition of norepinephrine to the muscle bath. Asterisks indicate a statistically significant difference between non-diabetic and diabetic patients (Student's $t$-test, $P<0 \cdot 05$ ). Values are the mean $\pm S E M$. The values in parentheses are the number of patients.

DOSE-RESPONSES TO NOREPINEPHRINE, SEROTONIN, ANGIOTENSIN II AND POTASSIUM CHLORIDE

Cumulative addition of norepinephrine $\left(5.9 \times 10^{-11}-5.9 \times 10^{-5} \mathrm{M}\right)$, serotonin $\left(7.8 \times 10^{-11}-2.6 \times 10^{-5} \mathrm{M}\right)$, angiotensin II $\left(10^{-11}-10^{-5} \mathrm{M}\right)$ and potassium chloride (7.5-100 $\mathrm{mM}$ ) to the muscle bath produced contractile responses in venous strips from diabetic and non-diabetic patients (Figs 2,3). Dose-response relationships for
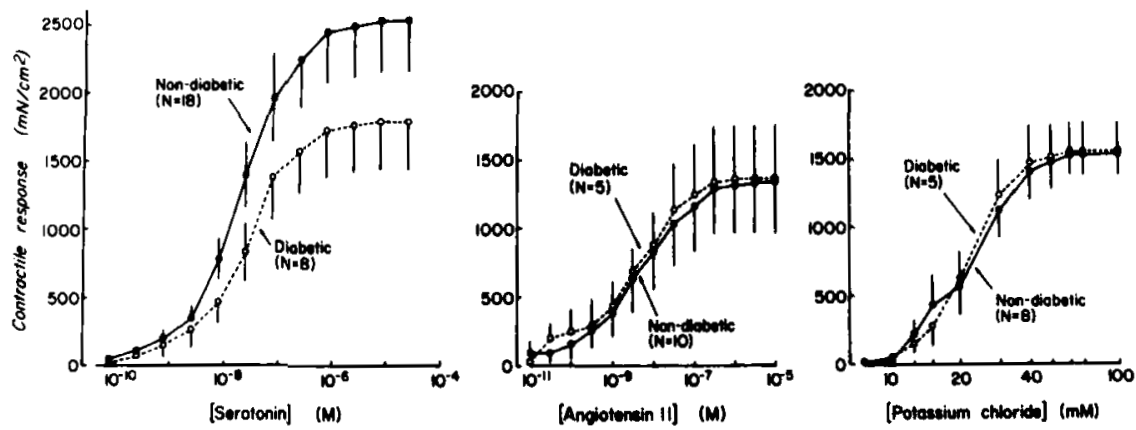

Fig. 3. Dose-response to serotonin, antiotensin II and potassium chloride. Helical strips of saphenous veins from non-diabetic and diabetic patients were made to contract in response to the cumulative addition of serotonin (left panel), angiotensin II (middle panel) and potassium chloride (right panel). Contractile responses to all three agonists in saphenous veins from diabetic patients were not statistically different from those in saphenous veins from non-diabetic patients. 
Table 2. $\mathrm{ED}_{\mathrm{s0}}$ values and maximal contractile responses

\begin{tabular}{|c|c|c|c|c|c|c|}
\hline & \multicolumn{2}{|c|}{$\mathrm{ED}_{50}$ values $(\mathrm{M})$} & \multicolumn{2}{|c|}{$-\log E D_{50}$ values } & \multicolumn{2}{|c|}{$\begin{array}{l}\text { Maximal tension developed } \\
\qquad\left(\mathrm{mN} / \mathrm{cm}^{2}\right)\end{array}$} \\
\hline & Diabetic & Non-diabetic & Diabetic & Non-diabetic & Diabetic & Non diabetic \\
\hline Norepinephrine & $4.3 \times 10^{-8}$ & $4.8 \times 10^{-8}$ & $\begin{array}{c}7 \cdot 367 \pm 0 \cdot 146 \\
(n=8)\end{array}$ & $\begin{array}{c}7 \cdot 319 \pm 0 \cdot 056 \\
(n=18)\end{array}$ & $\begin{array}{c}1180 \pm 237^{*} \\
(n=8)\end{array}$ & $\begin{array}{c}2169 \pm 343 \\
(n=18)\end{array}$ \\
\hline Serotonin & $2.5 \times 10^{-8}$ & $2 \cdot 3 \times 10^{-8}$ & $\begin{array}{c}7 \cdot 609 \pm 0 \cdot 118 \\
(n=8)\end{array}$ & $\begin{array}{c}7 \cdot 635 \pm 0.064 \\
(n=18)\end{array}$ & $\begin{array}{c}1784 \pm 348 \\
(n=8)\end{array}$ & $\begin{array}{c}2523 \pm 370 \\
(n=18)\end{array}$ \\
\hline Angiotensin II & $0.2 \times 10^{-8}$ & $0.5 \times 10^{-8}$ & $\begin{array}{c}8 \cdot 613 \pm 0 \cdot 304 \\
\quad(n=5)\end{array}$ & $\begin{array}{c}8 \cdot 285 \pm 234 \\
(n=10)\end{array}$ & $\begin{array}{c}1355 \pm 415 \\
(n=5)\end{array}$ & $\begin{array}{c}1333 \pm 350 \\
(n=10)\end{array}$ \\
\hline Potassium chloride & $2 \cdot 1 \times 10^{-2}$ & $2.3 \times 10^{-2}$ & $\begin{array}{c}1 \cdot 673 \pm 0 \cdot 058 \\
(n=5)\end{array}$ & $\begin{array}{c}1 \cdot 648 \pm 0 \cdot 057 \\
(n=8)\end{array}$ & $\begin{array}{c}1555 \pm 216 \\
(n=5)\end{array}$ & $\begin{array}{c}1534 \pm 152 \\
(n=8)\end{array}$ \\
\hline
\end{tabular}

$\mathrm{ED}_{50}$ values (first two columns) are the anti-log of geometric means presented for respective groups. The $-\log E D_{50}$ values were determined following logit $-\log$ transformation (see Methods). Values are the mean \pm SEM. The values in parentheses are the number of patients. The asterisk indicates a statistically significant difference between patient groups (Student's $t$-test; $P<0.05$ ).

norepinephrine and serotonin were determined for all venous strips whereas those for angiotensin II and potassium chloride were determined in venous strips from five diabetic patients and 8-10 non-diabetic patients. Additionally, maximal force generation to $100 \mathrm{mM}$ potassium chloride was determined in all venous strips which were not characterized by the cumulative dose-effect of this contractile agonist.

Maximal tension developed in response to norepinephrine was decreased in saphenous veins from diabetic patients compared to that in veins from non-diabetic patients (Fig. 2 and Table 2). Saphenous veins from diabetic patients also developed consistently less maximal tension in response to serotonin (Fig. 3 and Table 2) than those from non-diabetic patients although this difference was not significantly different on a statistical basis. Maximal tension developed in response to angiotensin II and potassium chloride in saphenous veins from five diabetic patients was not statistically different from that in veins from 8-10 non-diabetic patients (Fig. 3 and Table 2). In these experiments which examined contractile effects of angiotensin II and serotonin, the venous strips from diabetic patients showed significantly reduced maximal responses to norepinephrine $\left(1141 \pm 253 \mathrm{mN} / \mathrm{cm}^{2} ; n=5\right)$ but not to serotonin $\left(1791 \pm 565 \mathrm{mN} / \mathrm{cm}^{2} ; n=5\right)$ compared to that in venous strips from non-diabetic patients $\left(2473 \pm 575 \mathrm{mN} / \mathrm{cm}^{2} ; 2180 \pm 595 \mathrm{mN} / \mathrm{cm}^{2}\right.$, respectively; $\left.n=10\right)$ suggesting that these experiments did not constitute a clinically relevant subgroup. Maximal tension development to $100 \mathrm{mM}$ potassium chloride for venous segments from diabetic patients not used in the dose-relationship analysis $\left(1385 \pm 296 \mathrm{mN} / \mathrm{cm}^{2} ; n=3\right)$ was not statistically different from that in similar venous segments from nondiabetic patients $\left(1403 \pm 126 \mathrm{mN} / \mathrm{cm}^{2} ; n=10\right)$. Maximal tension to potassium chloride in strips used for determining the dose-dependent effects of the contractile agonist did not differ from 
these values determined by single dose analysis (compare above values with those reported in Table 2). Grouping the observations for maximal tension to potassium chloride from both experimental determinations yielded the following average values: diabetic patients $(n=8)=1481 \pm 173 \mathrm{mN} / \mathrm{cm}^{2}$; non-diabetic patients $(n=18)=1461 \pm 94$ $\mathrm{mN} / \mathrm{cm}^{2}(P>0 \cdot 05)$.

In order to compare sensitivity to the agonists between the two patient groups, the values reported in Figs 2 and 3 were normalized to per cent maximal response and the dose of the agonist producing a half maximal response was calculated. The doses of each drug which produced half-maximal responses $\left(-\log \mathrm{ED}_{50}\right.$ values) in saphenous veins from diabetic patients were not statistically different from those in veins from non-diabetic patients (Table 2).

As reported in the Methods section, several of the patients involved in this study were being treated for hypertension (four non-diabetic patients and three diabetic patients). Contractile responses of vein segments from these subjects were not significantly different from those of other venous strips within their respective subgroups (data not shown).

\section{Discussion}

Experimental evidence suggests that the responsiveness of the vasculature in diabetes to vasoactive drugs is altered compared to that in controls (for review, see Altura, Halevy \& Turlapaty, 1979; Chobanian et al., 1982; West, 1978). The observations of different studies are highly variable suggesting that reported differences may be influenced by the following: (1) animal species; (2) in vivo versus in vitro conditions; (3) resistance vessel versus large vessel differences; (4) the type of diabetes (experimental (streptozotocin-induced versus alloxan-induced) versus clinical); (5) the duration and/or severity of the diabetic state; and (6) the vasoactive agents tested. To our knowledge, this is the first study that characterizes smooth muscle reactivity in isolated vascular segments from diabetic patients.

Saphenous veins from diabetic patients developed less maximal tension in response to norepinephrine than those from non-diabetic patients. Maximal tension development to seroronin in veins from diabetic patients was consistently less than that in veins from non-diabetic patients but the difference was not statistically significant. The cellular mechanism leading to this depressed maximal response to norepinephrine in diabetes is unclear. The diabetic venous strips were not at a lower point on their length-tension curve than those from non-diabetic patients. The optimum passive force for maximum response to norepinephrine was similar for venous strips from diabetic and non-diabetic patients $(\sim 20.0 \mathrm{mN})$. Furthermore, a difference in the length-tension relationship would be predicted to result in a generalized change in contractility. Since smooth muscle reactivity to angiotensin II and potassium chloride in saphenous veins from diabetic patients was not statistically different from that in veins from non-diabetic patients, the results suggest that a 
specific change in force-generating ability in response to alpha-adrenergic receptor activation (and possibly serotonergic receptor activation) occurs in veins from diabetic patients.

One possible cause of the difference in adrenergic responsiveness in diabetic veins is an increase in the neuronal uptake mechanism of nerve endings present in the blood vessel wall. Neuronal uptake of norepinephrine plays a role in catecholamine disposition (Vanhoutte, Verbeuren \& Webb, 1981; Webb, Vanhoutee \& Bohr, 1980) and an increase in its activity could decrease receptor activation producing reduced contractile responses. This seems unlikely since changes in neuronal uptake activity are not usually accompanied by altered maximum force-generating ability (Vanhoutte, Verbeuren \& Webb, 1981; Webb, Vanhoutte \& Bohr 1980) and changes in the function of adrenergic nerves are usually associated with changes in catecholomine sensitivity (Bevan, Bevan \& Duckles, 1980; Vanhoutte, Verbeuren \& Webb, 1981; Webb, Vanhoutte \& Bohr, 1980). The sensitivity (- $\log E D_{50}$ values) to norepinephrine of saphenous vein strips from diabetic patients was not statistically different from that in veins from non-diabetic patients (Table 2).

Another possible explanation for reduced adrenergic responsiveness of venous strips from diabetic patients is an increased beta-adrenergic component. Contractile responses to norepinephrine are the sum of alpha-adrenergic receptor-mediated contraction and beta-receptor mediated-relaxation. An increased beta receptormediated component could result in a reduced contractile response if the number and affinity of alpha-adrenergic receptors remained constant. This seems an unlikely explanation since increased beta-adrenegic activity would probably decrease alphaadrenergic sensitivity (rightward shift in the normalized dose-response curve; Bevan, Bevan \& Duckles, 1980).

It seems likely that the decreased maximum force generating ability of venous strips from diabetic patients to norepinephrine is caused by a reduction in some component of the contractile sequence following alpha-receptor activation. The basis for this conclusion is that contractile responses to the agonists used in this study depend on different mechanisms to produce contraction. For example, elevated potassium concentration causes membrane depolarization, and the contractile response is the result of an influx of extracellular calcium into the cell (Bohr, 1973; Weiss, 1981). In contrast, norepinephrine-induced contractions are caused by an initial release of intracellularly bound calcium followed by an increased cellular membrane permeability to the cation. Based on studies with calcium channel blockers (Bohr, 1973; Weiss, 1981), it is likely that the calcium channels opened by a change in membrane potentinal are different from those opened in response to alpha-adrenergic receptor activation. A reduction in the number of calcium channels opened by alpha-adrenergic receptor activation may explain reduced maximal force generation to norepinephrine in saphenous veins from diabetic patients.

In the present study, saphenous vein strips from non-diabetic patients exhibited a greater incidence of spontaneous phasic contractile activity than did those from 
diabetic patients. These phasic contractions were not blocked by phentolomine, suggesting that the contractions were not caused by leakage of norepinephrine from adrenergic nerve endings in the vessel wall. Calcium-free solution containing EGTA and the calcium channel blocker, D-600, abolished the phasic contractions. The magnitude of the phasic contractile responses in saphenous veins from the diabetic patient were not different from those in veins from non-diabetic patients. Since the incidence of these calcium-dependent contractions are reduced in diabetes, these observations provide further evidence for a change in calcium handling by the cellular membrane of smooth muscle cells in saphenous veins from diabetic patients.

\section{References}

Altura B. M., Halevy S. \& Turlapaty P. D. M. V. (1979) Vascular smooth muscle in diabetes and its influence on the reactivity of blood vessels. Adv Microcir, 8, 118-150.

Beretta-Piccoli C. \& Weidmann P. (1981) Exaggerated pressor responsiveness to norepinephrine in nonazotemic diabetes mellitus. Am J Med, 71, 829-835.

Bevan J. A., Bevan R. D. \& Duckles S. P. (1980) Adrenergic regulation of vascular smooth muscle. In: Handbook of Physiology, The Cardiovascular System. Sec 2, Vol II (eds. Bohr D. F., Somlyo A. P. \& Sparks H. V. Jr.), pp. 515-566. Physiol Soc, Bethesda, MD, U.S.A.

Bohr D. F. (1973) Vascular smooth muscle updated. Circulation Res, 32, 665-672.

Brody M. J \& Dixon R. L. (1964) Vascular reactivity in experimental diabetes mellitus. Circulation Res, 14, 494-501.

Christlek A. R. (1974) Renin, angiotensin and norepinephrine in alloxan diabetes. Diabetes, 23, 962-970.

Christlueb A. R., Janka H.-V., Kraus B., Gleason R. E., Kasas-Cobral E. A., Aiello L. M., Cabral B. R. \& Solano A. (1976) Vascular reactivity to angiotensin II and to norepinephrine in diabetic subjects. Diabetes, 25, 268-274.

Chobanian A. V., Arquilla E. R., Clarkson T. R., Eder H. A., Howard C. F., Regan T. J. \& Williamson J. R. (1982) Cardiovascular complications. Diabetes, 31 (Suppl. 1), 54-64.

Cseuz R., Wenger T. L., Kunas G. \& Szentivany M. (1973) Changes of adrenergic reaction pattern in experimental diabetes mellitus. Endocrinology, 93, 752-755.

FoY J. M. \& Lucas P. D. (1976) Effect of experimental diabetes, food deprivation and genetic obesity on the sensitivity of pithed rats to autonomic agents. Br J Pharmac, 57, 229-234.

Joyner W. L., Mayhan W. G., Johnson R. L. \& Phares C. K. (1981) Microvascular alterations develop in Syrian hamsters after the induction of diabetes mellitus by streptozotocin. Diabetes, 30, 98-100.

KaUl C. L. \& Grewal. R. S. (1980) Vascular reactivity in streptozotocin induced diabetic rats. Pharmac Res Commun, 12, 945-958.

OWEN M. P. \& CARRIER G. O. (1980) Calcium dependence of norepinphrine-induced vascular contraction in experimental diabetes. $J$ Pharmacol exp Ther, 212, 253-258.

Sullivan S. \& Sparks H. V. (1979) Diminished contractile response of aortas from diabetic rabbits. Am J Physiol, 236, H301-H306.

Vanhoutte P. M., Verbeuren T. J. \& Webr R. C. (1981) Local modulation of the adrenergic neuroeffector interaction in the blood vessel wall. Physiol Rev, 61, 151-247.

Webs R. C., Vanhoutte P. M. \& Bohr D. F. (1980) Inactivation of released norepinephrine in rat tail artery by neuromal uptake. J Cardiovasc Pharmacol, 2, 121-132.

Weidmann P., Beretra-Piccoli C., Keusch G., Gluck Z., Mujagic M., Grimm M., Meir A. \& Ziegler W. H. (1979) Sodium-volume factors, cardiovascular reactivity and hypotensive mechanism of diuretic therapy in mild hypertension associated with diabetes mellitus. Am J Med 67, 779-784.

Weiss G. B. (1981) New Perspectives on Calcium Antagonists. Waverly Press, Baltimore.

WEST K. M. (1978) Epidemiology of Diabetes and its Vascular Lesions. Elsevier/North Holland Biomedical Press, Amsterdam. 